\title{
INTEGRATION STRATEGIES FOR THE SUCCESS OF MERGERS AND ACQUISITIONS IN FINANCIAL SERVICES COMPANIES ${ }^{1}$
}

\author{
Rafael Hernandez Barros', Ignacio López Domínguez² \\ ${ }^{1}$ Corporate Finance Departament, Faculty of Economics and Business Sciences \\ (Campus de Somosaguas), Universidad Complutense de Madrid, \\ 28223 Pozuelo de Alarcón, Madrid, Spain \\ ${ }^{2}$ Economics and Business Departament, Faculty of Social Sciencies \\ (Campus de la Dehesa de la Villa), Universidad Antonio de Nebrija. C/ Pirineos 55, \\ 28040 Madrid, Spain \\ E-mails: ${ }^{1}$ rafaeljh@ucm.es (corresponding author); ${ }^{2}$ ilopezd@nebrija.es
}

Received 30 Machr 2013; accepted 09 May 2013

\begin{abstract}
The research shows how managers can plan a successful integration process following a merger and acquisition. Presents a series of frameworks which discuss understanding value creation in mergers and acquisitions, selecting the right strategy and managing the integration process; drawn largely from research studies and interviews made to managers with experience in leading integration processes of financial services companies in Europe, Latin America and USA. Concludes that, by following the key drivers framework described, managers can turn the integration process into a successful project, and academics can focus their post-merger research having into account the opinion of managers.
\end{abstract}

Keywords: mergers and acquisitions, post-merger integration, value creation, synergies.

Reference to this paper should be made as follows: Hernandez Barros, R.; López Domínguez, I. 2013. Integration strategies for the success of mergers and acquisitions in financial services companies, Journal of Business Economics and Management 14(5): 979-992.

JEL Classification: G20, G34.

\section{Introduction}

Are merger and acquisitions (M\&A) successful in value creation? In corporate finance there is much controversy whether M\&A creates value or not (Ghosh 2001), and many empirical studies have shown both, that create value as they do not (Moller et al. 2005), in different sectors and with different reasons to make the integration (Goedhat et al. 2010). The aim of this paper is to show that, to succeed in creating value in M\&A, and once it has been made or decided by shareholders, the integration process following

\footnotetext{
${ }^{1}$ This research is the result of a collaborative work of more than three years between the Departments of Economía Financiera y Contabilidad III (Universidad Complutense de Madrid) and Economía y Administración de Empresas (Universidad Antonio de Nebrija).
} 
the merger should focus on revenue and customers, and not as has been done so far by the academic literature and financial analysts, who put the emphasis on the brand, cost reduction or talent management, and it is explored through the description of the results of interviews made to managers who have led integration processes in financial services companies in Europe, Latin America and USA.

Mergers and acquisitions of all types and sizes have a great impact on organizations, strategy and people (Birkinshaw et al. 2000), because they create the maximum possible value (King, Dalton 2004), a term often used by companies in their mission statements that equally concerns managers, analysts, and researchers (Pablo, Javidan 2004). To achieve these objectives and to preserve revenue expectations after mergers and acquisitions, top management have different strategies and tools (Galpin, Herndo 2007) (Schweiger 2010) to maintain competitive advantages and produce sustainable cash flows (Zollo, Singh 2004), whose main engines are the generation of revenues and value to customers, the maintenance of efficient operations and the attraction of talent.

Value creation is the increase in shareholder value over the expectations reflected in the return required by shareholders. There are many drivers that create value (Harris 2010), such as competitive advantage, global negotiations (Saeea 2008), the regulatory framework, taxation, line of business, barriers to entry, operational and financial risk, among others (Fernández 2005), being revenues as the basic source of cash flow generation (Mascareñas 2011), though more revenue not necessarily implies more cash flow or value creation (Krishnan et al. 2007). Revenues in itself justifies the rest of the activities and operations of the company (Homburg, Bucerius 2005) and drives job creation and GDP, but it is usually diluted when planning the integration of companies because of the focus on business support activities, organizational issues, and reducing costs and staff size (Bekier, Shelton 2002). Thus, by reading the paper it will be discovered the importance of revenue synergies as the main variable to consider when focusing on integration following an acquisition, which will have to guide the policies and operations to perform with the rest of the organizational variables, systems, and people for the integration to work so that value creation will materialize successfully.

The paper is designed for researchers in the field of corporate finance and M\&A who are seeking how to seize the value creation of M\&A, focusing on the problem currently faced by researchers (how to set the strategy for the integration of M\&A for its success). Additionally, the present work, using the opinion of managers, shows how to remove some of the obstacles that follow a M\&A, and also reveals how researchers can use the new findings to obtain the desired results in the value creation of M\&A in spite of cost reduction pressures. To demonstrate all this, the paper covers the following sections in this order: background, method and its review, findings and its analysis, ad implications and conclusions.

\section{Background}

As professors of finance and business economics, we realized that the M\&A subject in the graduate courses of Business Administration in Spain covered in a very limited way the post-merger integrations, and all issues of the process have the same treatment, 
without any scheme or drivers; there was missing something. Furthermore, regarding our professional experience in the financial services industry, we have always seen that managers who led mergers focus stubbornly on revenue and customers, so we decided, with the intuition that something meaningful could be contributed to the financial literature, to start a exploratory research to corroborate that in the integrations, as in the day to day business, the focus has to be set on customers, trying to provide a scheme draft by which managers could be identified and academics could use to further research in areas that will continue to help companies in the task of creating value and integrating successfully.

With this background and the lack of specific research literature on the processes of post-merger integration and the opinion of management, the idea was to carry out an exploratory research to confirm our initial impressions of the integration processes and substantiate them before proceeding with more in-depth research on mergers, the reasons to perform them and the results in the markets.

\section{Method: qualitative interview to managers}

The general approach of this exploratory research was to conduct qualitative interviews with managers (in total there were 28), who lead or had led integration processes, using our contacts and directors of financial services companies in Europe, Latin America and USA with whom we have relationship for our professional occupations, as well as alumni from IESE Business School (University of Navarra) and, in particular, alumni from Universidad Complutense de Madrid and Universidad Antonio de Nebrija, where we lecture. We had no intention whatsoever that the sample were perfectly representative of the sector or the countries chosen, although we have achieved a reasonable range.

We used a basic outline as a guide for the interviews, rather informal and open about their experience, the type of businesses and the integration projects, with the idea of collecting all the nuances of their opinions and comments. The interviews lasted on average about two hours and were conducted in person and by telephone.

\subsection{Scope and sample design}

The scope, therefore, was to have the vision of the directors of financial services companies, those who are in charge of the day to day of the business, before and after the merger, and so try to find a conceptual scheme, if it existed, through the reality of companies with the integrations, which was of general application. A summary of the sample is described in Table 1.

On one side, we were finding that business managers were focused on revenue and customers, but the financial literature and analysts were paying attention on the back office or other pillars of business success, such as talent, perhaps influenced by the short term financial targets and by the reasons which had come the company to take the decision to perform the M\&A.

This paper will not prove financially with market data if companies that focus on certain strategies create value or not, this is left for future research. It could be done in 
two ways: by identifying who is successful in creating value and see their strategies, or analyze the companies that use the strategy of revenue in the integrations, and analyze the results obtained in the creation of value in the markets.

Table 1. Description of sample

\begin{tabular}{|c|c|c|c|c|}
\hline Company & Subsector & Company size & Country & Responsibility \\
\hline 1 & Banking & Medium & Chile & $\mathrm{CFO}$ \\
\hline 2 & Banking & Medium & France & BL Manager \\
\hline 3 & Banking & Medium & France & BL Manager \\
\hline 4 & Banking & Medium & Mexico & BL Manager \\
\hline 5 & Banking & Medium & Spain & General Manager \\
\hline 6 & Banking & Large & UK & $\mathrm{CFO}$ \\
\hline 7 & Banking & Large & UK & BL Manager \\
\hline 8 & Banking & Medium & USA & BL Manager \\
\hline 9 & Banking & Medium & USA & BL Manager \\
\hline 10 & $\begin{array}{l}\text { Consulting firms } \\
\text { in financial services }\end{array}$ & Medium & France & BL Manager \\
\hline 11 & $\begin{array}{l}\text { Consulting firms } \\
\text { in financial services }\end{array}$ & Medium & Mexico & CEO \\
\hline 12 & Financial advisory & Small & Argentina & BL Manager \\
\hline 13 & Financial advisory & Small & Portugal & BL Manager \\
\hline 14 & Financial advisory & Small & Spain & BL Manager \\
\hline 15 & Financial advisory & Small & USA & General Manager \\
\hline 16 & Financial advisory & Medium & Venezuela & General Manager \\
\hline 17 & Insurance & Medium & Argentina & $\mathrm{CFO}$ \\
\hline 18 & Insurance & Medium & Brazil & BL Manager \\
\hline 19 & Insurance & Large & Colombia & BL Manager \\
\hline 20 & Insurance & Medium & Portugal & BL Manager \\
\hline 21 & Insurance & Medium & Spain & $\mathrm{CFO}$ \\
\hline 22 & Insurance & Large & Spain & BL Manager \\
\hline 23 & Insurance & Medium & USA & BL Manager \\
\hline 24 & Insurance & Medium & USA & BL Manager \\
\hline 25 & Investment management & Medium & Brazil & BL Manager \\
\hline 26 & Investment management & Small & Spain & BL Manager \\
\hline 27 & Investment management & Small & UK & BL Manager \\
\hline 28 & Investment management & Medium & USA & General Manager \\
\hline
\end{tabular}

Notes: * Company size: regarding number of employees: Small - Less than 500 employees; Medium Between 500 and 1.000; Large - More than 2.500.

** BL: Business Line. 
The research is centered on financial services companies (banking, insurance, consulting firms in financial services, financial advisory and investment management) in Europe (Spain, France, Portugal and UK), Latin America (Argentina, Brazil, Colombia, Chile, Mexico and Venezuela) and USA, because it is the area of expertise and contacts of the authors, where they provide added value with their experience and knowledge. The conclusions are somewhat applicable to other sectors, but would have to incorporate in future research aspects such as assets and manufacturing processes in the integration strategies along with revenue and customers.

While important, the benefits of cost reduction and talent management in the integrations will not be addressed, as there is much literature, as mentioned above.

\subsection{Execution and limitations}

In general, interviews were held for almost six months, from June 2012 to November 2012, with very satisfactory results both in the initial contacts and in its development: managers were open to talk about their experiences and give advice on how to develop the research.

The main limitations of the approach are those of the methodology (qualitative interviews with executives), because the sample was relatively small (28 interviews), interviews relatively short (about two hours), some by phone, they do not capture the extent or the nuances with which the author would have liked, but with the conviction that it was only exploratory research.

There may also be some bias because managers are business managers, front office, which has its priorities in creating value for companies in financial services: the customer and revenue, and because cost reduction always affects in a major way to back office, as support services, technology and wage increases.

\section{Findings on integration success}

The approach of this section is to present the findings and its analysis about the answers and opinions of the managers interviewed on integration processes that follow a merger or acquisition. In the first place it is addressed the significance of revenue synergies in mergers and acquisitions and the main aspects to consider before the integration is made, such as aligning the implementation strategy with the reasons for the merger. Then the most important findings on the integration activities are presented, both in its organizational and structural side, which is a necessary base to prepare for the success of the commercial and client integration.

\subsection{Finding 1. Prominence of income in the creation of value in mergers and acquisitions}

From the financial point of view of companies, mergers and acquisitions are a typical investment decision, whose value depends on a set of assumptions about the future generation of flows and their risk, undertaken in hopes of extracting more value from it than its current owners. The main source, although not the only one, of this generation of cash or value creation in companies, is the earnings, which in themselves justify the rest of the 
activities and operations of the company and is considered by the directors interviewed to be the main objective in virtually all merger announcements they were involved in.

In general, all the reasons referred by managers to carry out mergers and acquisitions take into account implicitly the income or the production of the acquired company. They refer as the common main objectives the following ones: horizontal integration for cost reduction; consolidation of fragmented markets to achieve economies of scale; vertical integrations to facilitate coordination, optimization of resource management and production capacity; or internal change, among others cited by managers. This means that revenue has to be integrated to maintain the generation of cash flows, although the explicit objective that motivated the acquisition was another one.

In particular, there are specific reasons that rely more heavily on income as the main element that justifies the creation of shareholder value in mergers. These include horizontal integration of a combination of products or services, forward vertical integration to approach customers, improved commercial management, access to strategic markets or business areas with potential for development, or even, implicitly, to combine resources such as innovation or leadership that would increase competitive advantage and direct sources of income generation.

There are certain aspects of the valuation and negotiation process prior to the realization of mergers and acquisitions that will affect future value creation, which are the usual limitations found in the estimated projections of revenue streams for the integration, particularly regarding the assumptions made about the generation of future income flows and their risks, which have to be kept in mind to avoid major pitfalls in the process of integration and avoid self-deception and disappointment among managers with the ex post results in terms of revenue growth.

But managers involved during the evaluation and negotiation process of some M\&A, point out that the most important limitation is that the acquisition, or the reasons for it, is not aligned with the business objectives and strategy in general or with the commercial policy and customer service in particular. If this happens, little can be done for the integration to be successful in terms of creating shareholder value. Other commons limitations and temptations mentioned are the optimistic scenarios in terms of revenue, such as the ones materialized in hypotheses of growth, cross-selling, estimating prices and market shares, to make the purchase seem reasonable or within the financial limits set by the parent company, as well as forgetting that it takes time to take advantage of revenue synergies, and that competition will try to take advantage of or respond to this new situation of uncertainty.

In summary, when it is not paid due attention to customers during the integration, there is likely to be more negative effects on the integrated company than the positive impact of cost savings. Any minimal negative impact on revenue growth may require that the cost objectives have to be adjusted by an additional percentage to justify the acquisition benefits, a very complicated task after the adjustments being made, which may jeopardize the foundations for future revenue growth. This highlights once again the imperative to maintain the growth of revenue streams and of the ways of implementing it, which is presented in the next finding. 


\subsection{Finding 2. Revenues and clients as drivers of the integration strategy}

The integration of customers and of the commercial area of the acquired company, to be effective following the opinion of managers, must be planned taking into account both organizations, at all levels, with respect to the policies, people, and culture of the company as well as in its structure and processes, which should be addressed from the general view of the entire company. To do this, several factors that affect income must be considered, such as the monitoring of policies, strategies, and internal procedures that are in place to align the new organization properly, guide and train sales staff in the common goals, and consolidate the customer service culture, including the type of division of labor and the establishment of dependency relationships between roles and responsibilities.

These organizational factors are very important (Tetenbaum 1999), and to a greater degree if the size of the acquired company is similar to ours because, if it is not formalized with a certain organization, the company is exposed to an even larger threat, creating companies that are very vulnerable with respect to the risk probability of loss of customers and declining revenues. The overall supervision of the income integration project requires an organization that makes it possible to assess these variables simultaneously, both the more displayable or formal (strategy, structure, or support systems and processes) and the more intangible or informal (people, shared values, the skills of both companies, and the management style). Together, these factors seem to determine how an organization operates, and ensure a successful implementation, all of these variables must be considered: they are all interdependent; if one fails to pay proper attention to one of them, it can affect all the others, too. Moreover, the relative importance of each may vary with time, as stress by some directors interviewed acquisitions, companies usually focus, mainly of people, particularly.

It has also been suggested by a high percentage of managers $(82 \%)$ that, in financial services companies, wages represent the largest expense on the income statement, which is an essential activity for value creation on savings and synergies, but the focus has to be set on earnings and on the front office, particularly in the commercial policies (the sales network and the clients), without forgetting the back: looking first at the structures and operations, those activities that help others to sell or to manufacture, to ensure that the commercial network will work effectively and without bottlenecks.

During the negotiation process, as some managers remind us (14\% of the sample), decisions could have been made due to the pressure of the circumstances, either because there is no alternative strategy or there are narrow time limits, which could lead to overestimating the benefits of the merger and stretching the revenue projections and synergies to be achieved to the maximum, affecting the value-creation capabilities. One of the things suggested to prevent this to happen is to include on the integration team legal and finance directors and people who are going to be in charge of the day-to-day business and could influence earnings: in other words, those who know the implications of making hasty or risky decisions during the negotiation.

Another fundamental aspect of the integration strategy that was recurrent by interviewees is the timing or speed: with a sense of urgency but neither too fast nor too slow. This 
is relevant because the board of directors has set its sights on creating value in the short term or in the annual closing so that, once the acquisition has been signed, one looks to the next objective and the creation of value is assumed. That is, with all activities and business fronts of a business line manager open, the merger tends to be just another part of a whole unless the firms or business units are of similar size, so in measuring the value creation of a single activity, that of the merger just completed, it makes sense to measure whether mergers are aligned with the strategy of creating value for the organization. The merger is a milestone in a timely strategy and, for certain activities, the life of the company follows and seeks new views, so the speed of integration is relevant; doing it soon and effectively enables the company to focus on its advantages and to continue to work as efficiently as possible.

\subsection{Finding 3. Organizational and back office issues, a supportive but second level priority}

With respect to operational and back office issues of the integration, which are the base that supports the vision and values (Yu et al. 2005) of the organization and always play an important role in meeting cost synergies to achieve the objectives of creating value from the acquisition, often cause stress to business managers because they do not understand that technical difficulties may affect or delay the project.

Furthermore, during the integration, managers complaint that much effort has to be set on preventing operational and back-office issues (such as systems, finance, human resources management, and legal aspects) from constraining the attention and resources of the project on the customers and the commercial aspects, providing resources and identifying the risks and causes that could cause income to not be produced. But the acquired company usually come with its business tools for managing the processes and reporting to management, often integrated with the customer data, which make it complex and difficult to integrate into the acquirer's information and internal control systems, especially if they use the Internet for communications with customers and suppliers, which have to be initially kept separate for the time required for the integration into the acquirer systems so the customers do not notice changes in the service level in the early stages of the merger.

A key aspect stressed in the interviews regarding the soft issues of the operational integration was the organizational alignment of the merging firms, the cultural and human convergence, both of the new company, which has to be adapted for the most part, and the acquirer, which has to digest the acquired company, which should be facilitated through training and other human resource practices. An aspect that is more difficult to manage is the conflict of culture, styles, and interests that arises due to the predictable and logical resistance to change arising from friction and power management in the early stages of the acquisition (Vaara 2003), reflecting the culture of each company and the common sense of each part, which always underlies the feeling of being winners and losers. 


\section{Resulting strategies for the success of commercial and client integration}

As noted throughout this paper, revenue growth is the main goal in the majority of mergers and acquisitions, and managers interviewed were particularly concerned with day-to-day operations of the newly integrated business, trying to focus on commercial and clients to maintain and develop the basic source of cash flows, as explained in the introduction, which is summarized in this section.

Following the opinion of managers, the proposed process or conceptual framework (Fig. 1), with the objective focused on the customer and revenues, is based on first having a clear understanding of what the board of directors or the integration leader wants to do with the two merged companies. For example, if it is to keep different brands and different sales teams that will lead each area and determine why or how the accounts will be distributed, a comprehensive action plan must be established. Then this strategy has to be communicated to the customers and the other key stakeholders, with the sales serving as the main channel of communica-

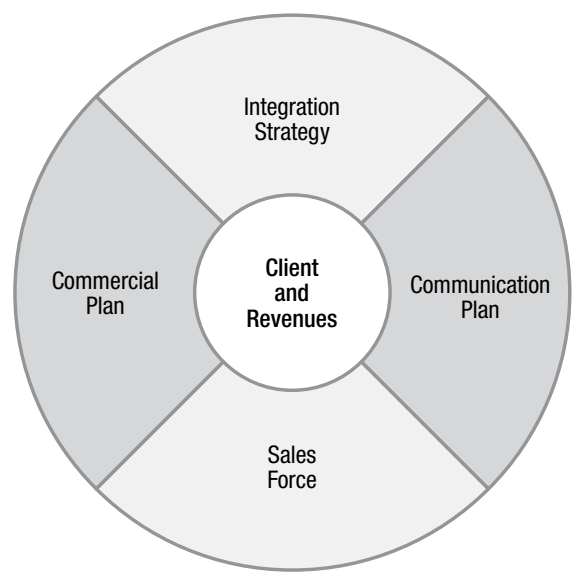

Fig. 1. Drivers of the integration process tion, as they will convey to the clients the essence of the merger and the integration (Thorbjørnsen, Dahlén 2011). It is also the sales team that must implement and develop, more specifically, the business plan, with a calendar of visits, the specific commercial actions to be taken with customers with greater risk of loss, or the identification of opportunities for synergies in sales, among others.

\subsection{Integration strategy}

It is possible that, in the moments close to the announcement of the merger, it may not yet be clear what business strategy is best able to capture the highest expected value creation in the acquisition process or that best suits the circumstances of both companies, but at least a road map needs to be established to indicate where the organization wants to go, where it is, and what is expected of the integration. The strategy could involve maintaining separate companies for a while or integrating them immediately; either way, the process will generate a number of uncertainties, primarily regarding the customers and the sales force, for which it is desirable to plan to avoid making incorrect decisions that could affect the future of the organization. This complexity stems from the different ways there are to serve customers and set prices, and it will impact the daily tasks of many people because selecting the best system for each company or using the management and processes of one over the other could lead to very different results. 


\subsection{Communication plan}

To succeed in the integration of customers and revenues, particular attention must be paid to the communication plan of the integration strategy, targeting customers, employees, managers, and other stakeholders, including analysts and investors, which must be ready to implement immediately, establishing open lines of communication from the bottom up and vice versa. These will vary over time and will have to be made through different channels, mainly to avoid organizational anxiety and uncertainty among customers, distributors, and suppliers. The communication plan will be coordinated or be a part of the general strategy for the communication policy of the company, acquiring more or less prominence depending on the impact of the acquisition on the organization and the market.

\subsection{Sales force}

Failure to pay enough attention to the human factor of the integration and to the different cultures could itself explain for some of the managers the failure of many acquisitions or at least be one of the reasons that some mergers do not go as planned. In particular, the sales staff would like to know whether the merger makes sense or not; how the company will change; how it will affect their job, their relationships, and their work-place; how the companies will operate, jointly or separately; how the accounts are going to be allocated; and whether the business objectives and their compensation will remain the same. Therefore, the most extensive part and the one that will require greater dedication in this communication plan involve the sales team. A direct relationship and information needs to be established by the integration team and its leader to generate enthusiasm and to ensure that the sales force, in turn, communicates a consistent and positive message to the customers and clears doubts and fears, making them feel that they are a crucial part of the company and the merger.

This is the first battle; if we earn the trust of the sales staff of both organizations, we are on the way to maintaining the customer base. The possibility that the sales force will be confused or distracted from focusing its efforts on other considerations or internal objectives has to be avoided because the customers will notice it. To do this, we must redefine and adapt the business organization, the revenue targets, and the reward schemes, including those of the directors, to the new situation, meeting their needs and concerns regarding the merger and rewarding them more than adequately or at least meeting their expectations and supporting them with specific resources for the merger in the case of any need or trouble with customers, service levels, or their team or distribution network and suppliers. This will also cause competitors to be less successful at recruiting key employees or with more skills and experience, including corporate account leaders.

There are a couple of additional issues that should be taken into account with respect to the sales staff. The first is to prevent the cost synergies of the integration project, which are mainly staff reductions, from affecting the ability to sell and subsequently impact post-acquisition performance, especially in the short and medium term. The other is the organization of the new team, the selection of managers or leaders of the various areas and departments, and the allocation of the rest of the commercial staff in the new scheme, trying to value the experience and capabilities of each individual and their adaptation to the new competitive and strategic situation. 


\subsection{Commercial plan}

Finally, the business plan is the tool that will allow us to realize in revenues the benefits expected from the merger. It is the moment for the different business teams to analyze the situation of the clients, or specialty areas, their contracts and service levels, the prices, services, and products, the distribution and logistics, and the quality of the supplies and the suppliers, and to review the tenders in progress, anticipate the cross-selling opportunities and identify the risk of loss for each client. This should be translated into a plan for visits with a specific agenda for dealing with customers, proposing, if necessary, alternative tenders or plans to renegotiate specific aspects of the contracts or service. To achieve this, the formation of a team dedicated to meeting the different commercial needs of the merger will help the sales force with their customer problems and in the coordination of efforts and resources, as well as access to commercial information and to management and billing tools.

Focusing the organizational efforts on the sales force, developing an integrated business plan and communicating it at all levels will help when confusion starts. Staff, customers, and other stakeholders will appreciate to be informed, motivated and reassured that the service delivery processes keep going. Otherwise, when a company loses its stakeholders trust, particularly that of the customer, it has been lost for a few years, causing time and effort to win them back.

\section{Implications and conclusions}

For researchers and analysts in corporate finance and mergers and acquisitions (M\&A), the findings above, much for its simplicity and common sense as for the methodology of collecting the best practices of managers who lead the integration of financial services companies, may benefit in general to focus their research to the needs of managers and companies in the integration processes, helping them to review and measure tangible criteria of value creation in M\&A, which was the aim of this paper, as stated in the introduction.

These findings and drivers' approach are also relevant to managers and professionals in general, because mergers and change is in the very nature of companies, so having a scheme based on the intuitively important on companies and in the best practices of what managers who lead international integration are doing managers, it can help them to think about the integration processes and improve them; it can also help managers to order what the literature says on the subject, which focus on other priorities, such as costs or the culture of the merged company, and give it the importance they deserve within the set of an integration and the objectives being sought to create value.

The public and professionals in general, with no background in the field of M\&A, could use the research to reconsider the merger processes that occur in all sectors and to analyze how it affects them, because all of us has to face, in some point in our lives, a merger as stakeholder (investor, worker or provider), and the findings may help them to predict how the way of carrying out an integration could impact the service and processes of the merged company, and show them the possibility to see mergers as a means of creating value for all stakeholders involved. 
Keeping customers and maintaining revenue is a necessary activity in the integration following mergers and acquisitions that presents ample opportunities for development and a large field for study regarding conceptual and practical issues because of the particularity and complexity involved in such implicit activities and strategies and the need to establish a framework that allows managers and academics to address the possible temptation to focus on the synergies of cost and staff reductions, a reality that is materialized in the destruction of shareholder value over the expectations reflected in the return required by shareholders in the vast majority of post-acquisition operations.

The problem of establishing a proper post-acquisition strategy has been treated from different points of view in the economic and financial literature. In particular, the importance of the integration of revenue and customers and their management as a key factor in creating shareholder value after mergers and acquisitions is not well known, which is the theme and objective of this research study, which could help fill this gap with its provision of a comprehensive conceptual framework focused on the source of cash flow generation: the customer.

Given that the analytical approach can be done from different points of view, the exercise and the whole process of identifying the key global aspects of the integration of customers and revenues through interviews to managers provides academics and professionals with a comprehensive view of the problem and a tool for its management and planning. With respect to customers in particular, it is not merely aimed toward seeking compliance with the standardized and independent tasks of all other activities of the organization, but is intended implicitly to facilitate the identification of the specific and different variables of each integration, achieving greater rigor in the management of the company as a whole against the problems associated with project integration and its impact on the generation of future cash flows, given that companies merge and will continue to do so for strategic and operational rationales.

Finally, we would like to remember the limitations and scope of this work: an exploratory research based on interviews with executives of financial services companies, but which could be used as a basis for deepening into the integration processes of companies in other sectors and for measuring their impact in creating value.

\section{References}

Bekier, M. M.; Shelton, M. J. 2002. Keeping your sales force after the merger, The McKinsey Quarterly 4: 106-115.

Birkinshaw, J.; Bresman, H.; Håkanson, L. 2000. Managing the post-acquisition integration process: how the human integration and task integration processes interact to foster value creation, Journal of Management Studies 37(3): 395-425. http://dx.doi.org/10.1111/1467-6486.00186

Fernández, P. 2005. Creación de valor para los accionistas: definición y cuantificación, Universia Business Review second quarter: 10-25.

Galpin, T. J.; Herndo, M. 2007. The complete guide to mergers and acquisitions: process tools to support $M \& A$ integration at every level. San Francisco: Wiley.

Ghosh, A. 2001. Does operating performance really improve following corporate acquisitions?, Journal of Corporate Finance 7(2): 151-178. http://dx.doi.org/10.1016/S0929-1199(01)00018-9 
Goedhat, M.; Koller, T.; Wessels, D. 2010. The five types of successful acquisitions, McKinsey on Finance 36: 2-7.

Harris, S. E. 2010. Lessons learned from a successful merger, Organizational Dynamics 39: 279-287. http://dx.doi.org/10.1016/j.orgdyn.2010.03.002

Homburg, C.; Bucerius, M. 2005. A marketing perspective on mergers and acquisitions: how marketing integration affects postmerger performance, Journal of Marketing 69(1): 95-113.

http://dx.doi.org/10.1509/jmkg.69.1.95.55510

King, D. R.; Dalton, D. R. 2004. Meta-analyses of post-acquisition performance: indications of unidentified moderators, Strategic Management Journal 25(2): 187-200.

http://dx.doi.org/10.1002/smj.371

Krishnan, H. A.; Hitt, A.; Park, D. 2007. Acquisition premiums, subsequent workforce reductions and post-acquisition performance, Journal of Management Studies 44(5): 709-732.

http://dx.doi.org/10.1111/j.1467-6486.2006.00672.x

Mascareñas, J. 2011. Fusiones y Adquisiciones de Empresas. Madrid: Ecobook.

Moller, S.; Schlingeman, F.; Stulz, R. 2005. Wealth destruction on a massive scale, Journal of Finance 60(2): 757-782. http://dx.doi.org/10.1111/j.1540-6261.2005.00745.x

Pablo, A. L.; Javidan, M. 2004. Mergers and acquisitions: creating integrative knowledge. Victoria, Australia: Blackwell Publishing Ltd.

Saeea, J. 2008. Best practice in global negotiation strategies for leaders and managers in the 21st century, Journal of Business Economics and Management 9(4): 309-318.

http://dx.doi.org/10.3846/1611-1699.2008.9.309-318

Schweiger, D. M. 2010. M\&A integration: a framework for executives and managers. New York: McGraw-Hill.

Tetenbaum, T. J. 1999. Beating the odds of merger \& acquisition failure: seven key practices that improve the chance for expected integration and synergies, Organizational Dynamics 28(2): 22-36. http://dx.doi.org/10.1016/S0090-2616(00)80014-5

Thorbjørnsen, H.; Dahlén, M. 2011. Customer reactions to acquirer-dominant mergers and acquisitions, International Journal of Research in Marketing 28(4): 281-388.

http://dx.doi.org/10.1016/j.ijresmar.2011.05.005

Vaara, E. 2003. Post-acquisition integration as sensemaking: glimpses of ambiguity, confusion, hypocrisy, and politicization, Journal of Management Studies 40(4): 859-894.

http://dx.doi.org/10.1111/1467-6486.00363

Yu, J.; Engleman, R. M.; Van de Ven, A. H. 2005. The integration journey: an attention-based view of the merger and acquisition integration process, Organization Studies 26(10): 1501-1528. http://dx.doi.org/10.1177/0170840605057071

Zollo, M.; Singh, H. 2004. Deliberate learning in corporate acquisitions: post-acquisition strategies and integration capability in U.S. bank mergers, Strategic Management Journal 25(13): 1233-1256. http://dx.doi.org/10.1002/smj.426 
Rafael HERNANDEZ BARROS is an Associate Professor at Universidad Complutense de Madrid, where he teaches corporate finance and organizational economics at master's and bachelor's levels. His research interests include mergers and acquisitions, financial management and organization theory. His work has been published in The Geneva Papers on Risk and Insurance, The Operational Risk Journal, International Business Research or Revista de Analisis Financiero. Rafael received his B.A. in Economics and Ph.D. in Finance from Universidad Autónoma de Madrid and earned his MBA at IESE Business School (University of Navarra). He also consults financial services companies on operations, organization and financial management.

Ignacio LÓPEZ DOMÍNGUEZ is currently Director of MBA programs at Nebrija Business School and full professor at Universidad Antonio de Nebrija, where he teaches financial management and business economics. His research interests are financial markets, family businesses and entrepreneurship. Ignacio serves as advisory board member at Business Banking (Editorial Firma de Informacion) and at Manager business journal, and is also Library Director of Management and Business at Editorial Cie Dossat 2000. He is a regular contributor in the media and in financial academic publications in Spain and Latin-America. Ignacio received his B.A. and Ph.D. in Economics from Universidad Autónoma de Madrid. He is also Vice President of the International Association of Management Studies (ASIEMA), Associate Consultant International Leadership Centre and Research Associate at the Institute for Development Economics Research (FIEC). 